\title{
Management of depression and related neuropsychiatric symptoms associated with HIV/AIDS and antiretroviral therapy
}

\author{
Mark Halman MD FRCPC
}

\begin{abstract}
M Halman. Management of depression and related neuropyschiatric symptoms associated with HIV/AIDS and antiretroviral therapy. Can J Infect Dis 2001;12(Suppl C):9C-19C.

Persons with HIV/AIDS may experience a wide range of neuropsychiatric symptoms, including depressed mood, anxiety, irritability, suicidal ideation, agitation and insomnia. These symptoms may be related to psychosocial stressors, biological diathesis to psychiatric syndromes, HIV-related medical illness and/or the medications used in the treatment of HIV/AIDS. Depressed mood is the most common neuropsychiatric complaint in persons with HIV/AIDS seeking psychiatric evaluation. Prevalence rates of major depression in persons with HIV/AIDS have been reported to range between $22 \%$ and $45 \%$. Despite the high prevalence, major depression remains underdiagnosed in patients with HIV/AIDS. Depression has a significant impact on quality of life, has a negative impact on antiretroviral adherence and is a significant risk factor for suicide.

With the advent of highly active antiretroviral therapy, HIV/AIDS has evolved into a chronic, manageable illness. The management of mental health concerns and neuropsychiatric symptoms has, therefore, become an integral part of comprehensive HIV/AIDS care. Clinical experience to date suggests that psychiatric syndromes in persons with HIV/AIDS and treatment-emergent neuropsychiatric side effects related to antiretroviral medications can be successfully managed using standard psychiatric interventions. The present article focuses on the treatment and management of major depression, including the choice of antidepressants and potential drug interaction considerations. Management of related symptoms of agitation and sleep disturbances are also reviewed.
\end{abstract}

Key Words: Antiretrovirals; Depression; HIV/AIDS

Pour le résumé, voir page suivante

HIV Psychiatry Program and the Medical Psychiatry Consultation Service, and Inner City Health Program, St Michael's Hospital; Department of Psychiatry, University of Toronto, Toronto, Ontario

Correspondence and reprints: Dr Mark Halman, St Michael's Hospital, Room 17038, Victoria Wing, 30 Bond Street, Toronto, Ontario M5B 1 W8. Telephone 416-864-3082, fax 416-864-5793, e-mail halmanm@mail.smh.toronto.on.ca 


\title{
Traitement de la dépression et des symptômes neuropsychiatriques associés au VIH/sida et au traitement antirétroviral
}

\begin{abstract}
RÉSUMÉ : Les personnes atteintes du VIH/sida peuvent éprouver divexs symptômes neuropsychiatriques, notamment un état dépressif, de l'anxiété, de l'irritabilité, des idées suicidaires, de l'agitation et de l'insomnie. Ces symptômes peuvent être liés aux facteurs de stress psychosociaux, à la diathèse biologique et aux syndromes psychiatriques, aux maladies secondaires au VIH ou au traitement du VIH/sida lui-même. La dépression est le symptôme neuropsychiatrique le plus fréquent qui motive une consultation en psychiatrie chez les personnes porteuses $\mathrm{du} \mathrm{VIH} / \mathrm{sida}$. La prévalence de la dépression majeure chez ces personnes varierait entre 22 et $45 \%$. Pourtant, malgré sa forte prévalence, la dépression reste sous-diagnostiquée dans cette population. Par ailleurs, la dépression a une incidence négative sur la qualité de vie et le respect du traitement antirétroviral, en plus de constituer un facteur de risque important de suicide.

Avec l'arrivée de la multithérapie, le VIH/sida est devenue une maladie chronique, susceptible de traitement. Aussi l'état de santé mentale et les symptômes neuropsychiatriques font-ils désormais partie intégrante du traitement global de la maladie. D'après l'expérience clinique acquise jusqu'à maintenant, les syndromes psychiatriques chez les personnes atteintes $\mathrm{du} \mathrm{VIH} / \mathrm{sida}$ et les effets neuropsychiatriques indési-rables, liés au traitement antirétroviral se prêtent bien aux interventions courantes en psychiatrie. Le présent article porte sur le traitement de la dépression majeure, y compris sur le choix des antidépresseurs et les interactions médicamenteuses possibles. Il sera aussi question du traitement de l'agitation et des troubles du sommeil liés à la maladie.
\end{abstract}

$\mathrm{P}_{\mathrm{r}}^{\mathrm{e}}$ ersons with HIV/AIDS may experience a wide range of neuropsychiatric symptoms, including subjective cognitive complaints; mood symptoms including depression, anxiety, irritability and suicidal ideation; and sleep disturbance and fatigue. Symptoms may be a reflection of the distress associated with the stressors of living with HIV/AIDS or may reflect a more specific psychiatric syndrome. The classic psychiatric syndromes associated with HIV/AIDS broadly include cognitive disorders such as delirium, HIV-associated dementia and minor cognitive motor disorder; mood disorders including major depression, often associated with prominent anxiety symptoms and frequently complicated by comorbid substance use, abuse and dependence; and psychoactive substance use disorders (1). Depressed mood as a symptom is the most common neuropsychiatric complaint in persons with HIV/AIDS seeking psychiatric evaluation (2), and has a broad differential diagnosis. Depressed mood may reflect the intrapsychic distress associated with living with HIV/AIDS, its inherent uncertainties and associated stigma (ie, adjustment disorder); may be associated with physiological changes directly associated with advanced medical illness (ie, mood disorder due to a general medical condition); or may be a symptom of a major depressive episode, a disorder characterized by persistently depressed mood and related symptoms such as sleep, energy and appetite disturbance, loss of interest and capacity to experience pleasure, diminished concentration, feelings of worthlessness, shame and diminished self-esteem, and recurrent thoughts of death including suicidal thoughts (Table 1) (3). Major depression results from a confluence of factors including a person's diathesis to developing depression and the psychosocial stressors that they are facing.

Neuropsychiatric symptoms, including depressed mood, agitation and insomnia, have been reported with several of the medications taken by patients with HIV/AIDS (4), such as lamivudine $(5,6)$, zidovudine $(7,8)$, interferon (9) and efavirenz (10-12). Many of the data lack diagnostic and associative rigour because they come from postmarketing case reports and clinical trial observations of treatmentemergent side effects, and are often reported as nonspecific psychiatric symptoms rather than as detailed syndromes. Also, they are usually evaluated by internists rather than psychiatrists, and is usually assessed without validated selfreport or other evaluated depression inventories. Management of these side effects and, specifically, management of depression are essential in providing comprehensive care for patients with HIV/AIDS. As yet, no studies have clarified whether the best treatment of antiretroviral-associated depression is to discontinue the associated antiretroviral agent or to continue with the antiretroviral therapy and manage the emergent psychiatric syndrome using standard psychiatric interventions. This question is further complicated by the limitations imposed by the patient's antiretroviral history, HIV-resistance pattern and other nonpsychiatric treatment-emergent side effects that may limit antiretroviral selection; these side effects include peripheral neuropathy, lipodystrophy, metabolic disturbances and gastrointestinal symptoms. From a clinical management standpoint, experience has demonstrated that most psychiatric symptoms, whether related to HIV/AIDS, antiretroviral medications, psychosocial factors or biological disposition, can be effectively managed in patients with HIV/AIDS using conventional psychiatric interventions described in the present review.

\section{DEPRESSION AND HIV/AIDS}

Prevalence rates of major depression in patients with HIV/AIDS have been reported to be between $22 \%$ and $45 \%$ (1317 ), with the variability being attributed to differing subject 


\section{TABLE 1}

\section{Diagnostic and Statistical Manual of Mental Disorders, Fourth Edition, Text revision criteria for a major depressive episode}

A. Five (or more) of the following symptoms have been present during the same two-week period and represent a change from previous functioning; at least one of the symptoms is either (1) depressed mood or (2) loss of interest or pleasure.

1. Depressed mood most of the day, nearly every day

2. Markedly diminished interest or pleasure in all, or almost all, activities

3. Significant weight loss or weight gain, or decrease or increase in appetite nearly every day

4. Insomnia or hypersomnia nearly every day

5. Psychomotor agitation or retardation nearly every day (observable)

6. Fatigue or loss of energy nearly every day

7. Feelings of worthlessness, or excessive or inappropriate guilt (may be delusional) nearly every day

8. Diminished ability to think or concentrate, or indecisiveness

9. Recurrent thoughts of death, recurrent suicidal ideation without a specific plan, a suicide attempt or a specific plan for committing suicide

B. The symptoms cause clinically significant distress or impairment in social, occupational or other important areas of functioning

C. The symptoms are not due to the direct physiological effects of a substance or a general medical condition (hypothyroidism)

Reprinted with permission from the Diagnostic and Statistical Manual of Mental Disorders, Fourth Edition, Text revision. Copyright 2000 American Psychiatric Association (reference 3)

samples, methodologies and screening measures used to evaluate depression (18). It is generally accepted that rates of major depression in persons with HIV/AIDS are higher than those seen in the general population (12-month prevalence $10.3 \%$ ) (19) and in primary care medical practices (point prevalence estimated at $10 \%$ ) (20). The prevalence of depression increases with later stages of HIV disease (21), and cohort prevalence appears to have only modestly decreased with the optimism surrounding the introduction of highly active antiretroviral therapy (HAART) (22). Despite the high prevalence, major depression remains underdiagnosed in patients with HIV/AIDS (23). Reasons for this may include a rationalization that depression is a logical and normal outcome of HIV/AIDS; that depression due to 'organic' conditions, such as HIV disease or medications, is unlikely to respond to antidepressant therapies; or that the somatic symptoms that accompany major depression - including sleep disturbance, fatigue, decreased appetite, weight loss, diminished concentration and poor libido - may be due to HIV disease itself rather than major depression. Therefore, the diagnosis is overlooked (24).

Risk factors for major depression include personal and family history of major depression, poor social support (25), limited coping capacities such as avoidance and denial (26), and progression of HIV/AIDS (27). The new realities of HIV/AIDS in the era of HAART treatments have introduced new psychological challenges and conflicts that may contribute to the distress of living with the illness. Patients have to undergo role transitions as they reformulate a future life plan with a chronic illness rather than a predictably fatal illness. Complex issues arise with respect to finances, return to work, access to insurance plans and lack of retirement planning. Antiretroviral regimen-related issues may also contribute to distress including exhaustion over lifelong adherence to medication and upset over side effects such as lipodystrophy changes, pain, nausea and chronic asthenia. Coping with the unpredictable durability of response and the limits of medical knowledge about the expected course of HIV disease in the era of HAART therapies is a source of distress that often underlies all others $(28,29)$.

\section{WHY TREAT MAJOR DEPRESSION?}

Major depression is a painful condition of persistent psychological distress, and the principal goal of treatment is to alleviate that pain, facilitate healing and improve functional outcomes (30). While distress and sadness are common features of HIV/AIDS, major depression is not a universal or expected feature of the illness and, when present, should be actively treated. Depression is a major factor associated with decreased quality of life in patients with HIV/AIDS, and major depression is a primary risk factor for suicide in both the general and HIV population $(31,32)$. In addition, major depression has been associated with decreased survival in HIV disease (33) and decreased immunological function (34). The recognition that a high rate of regimen fidelity is required to maintain long term viral suppression has led to increasing study of the factors affecting antiretroviral medication adherence. Several investigators have now reported that depression may interfere with adherence $(35,36)$, and treatment of depression may have a positive impact on adherence to therapy, ultimately leading to an overall improved health outcome (37). Depression is only one of several important psychosocial 


\section{TABLE 2}

Percentage of patients with treatment-emergent neuropsychiatric events of moderate or severe intensity reported in $2 \%$ or more of patients in Studies DMP 266-066, ACTG 364, and DMP 266-020

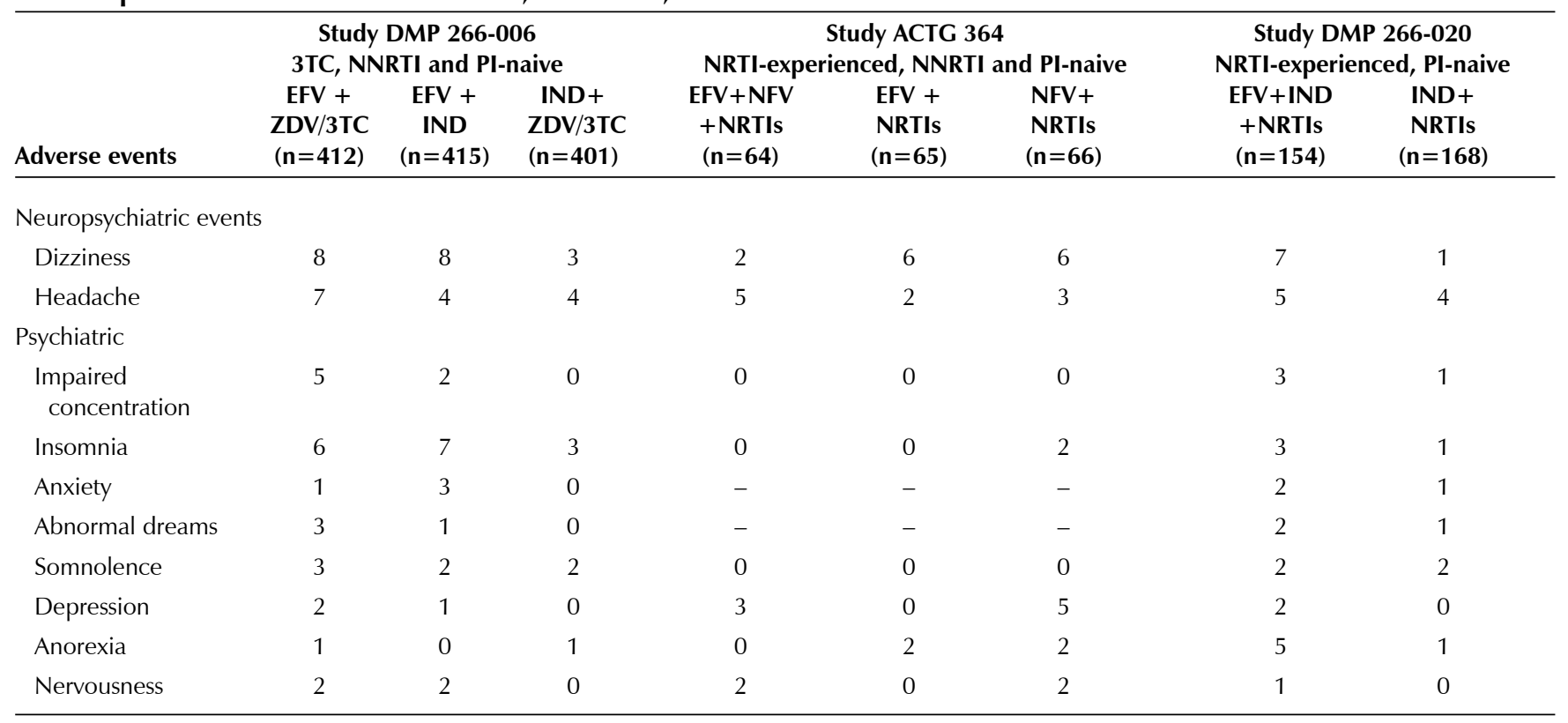

Data from reference 12. EFV Efavirenz; IND Indinavir; NFV Nelfinavir; NNRTI Non-nucleoside reverse transcriptase inhibitor; NRTI Nucleoside reverse transcriptase inhibitor; PI Protease inhibitor; 3TC Lamivudine; ZDV Zidovudine

variables, including social support and perceived self-efficacy, that may affect adherence and may respond to mental health interventions (38).

\section{EFAVIRENZ AND NEUROPSYCHIATRIC SYMPTOMS}

As HIV/AIDS becomes a more chronic manageable disease, increased attention is being paid to the treatment-associated side effects (39), including neuropsychiatric side effects and their management. Although there has been widespread awareness of the distress that accompanies HIV/AIDS and the fact that many of the medications used in treatment are associated with a variety of neuropsychiatric symptoms, it has been the association of neuropsychiatric side effects with the introduction of efavirenz and, in particular, concerns over emergent depression that have prompted an increased interest in better understanding the association and management of neuropsychiatric symptoms. In controlled trials evaluating the safety and efficacy of efavirenz, a mean $53 \%$ of patients experienced nervous system symptoms and less commonly psychiatric symptoms $(11,12,40)$. The most commonly reported symptoms were a feeling of being 'stoned', having vivid dreams and being anxious. Other reported symptoms included abnormal thinking, impaired concentration, amnesia, confusion, depersonalization, depression, agitation, euphoria, insomnia, somnolence and, rarely, hallucinations (Table 2) (12). Treatment-emergent neuropsychiatric side effects were usually reported soon after the first dose, with a median onset of one day, and generally subsided over the first one to four months of treatment. Compared with a non- efavirenz-containing regimen (zidovudine/lamivudine/indinavir) in the 006 study, there were more neuropsychiatric side effects in the efavirenz-containing protocol group $(53 \%$ versus 26\%) (11). Antiretroviral regimen discontinuation due to nervous system symptoms was higher, with $2.1 \%$ discontinuing efavirenz therapy compared with $1.1 \%$ in the nonefavirenz-containing treatment arms (12).

As the use of efavirenz has grown, data are accumulating about its safety in the nonclinical trials setting. Initial anecdotal impressions suggested that persons with mental health or psychiatric histories and/or substance use disorders may be at greater risk of developing efavirenz-related neuropsychiatric side effects. Recent data from community settings with a broad range of patients, including those with mental health and substance abuse disorders, have been reported. The reports are limited by their retrospective nature, small samples and methodology limitations, and are conference proceedings rather than peer-reviewed manuscripts. Nonetheless, they provide the first data that reflect use in a broader and more representative patient sample. In one low income community sample of 22 patients, of whom $73 \%$ had a mental health or substance use history, two (9\%) discontinued efavirenz due to neuropsychiatric side effects (41). Of note, 10 of 12 patients with psychiatric histories (principally depression) were currently receiving antidepressant treatment, but only four of 12 patients with substance-related disorders were substance free for longer than one year. A separate report of 175 subjects from a large urban clinic found $34 \%$ of subjects reporting at least one neuropsychiatric side 
effect and a discontinuation rate of $16 \%$. Principal reasons for discontinuation were dizziness, impaired concentration and sleep disturbance. In that sample, $21 \%$ of patients had injection drug use histories, $27 \%$ had other drug use histories, $19 \%$ had alcohol dependence histories and 30\% had psychiatric histories. Rates of treatment-emergent neuropsychiatric side effects and the associated discontinuation rates did not differ across the groups, nor did they differ from those of subjects with no mental health or substance use histories. Unfortunately, the data do not differentiate between lifetime and current histories, or treatment status of the mental health or substance use disorders in examining the association with emergence of neuropsychiatric side effects (42). Another retrospective review from a large American clinic reported on 400 subjects taking efavirenz, of whom $58 \%$ had lifetime histories of psychiatric disorders (principally mood and anxiety) and 56\% had lifetime histories of substancerelated disorders. In this group, $46 \%$ developed a psychiatric side effect, chiefly depression (48\%) and vivid dreams (22\%). The discontinuation rate secondary to psychiatric side effects was $6 \%$, and all psychiatric side effects were reported to have resolved with drug discontinuation or psychiatric treatment (43). Finally, using a structured psychiatric symptom checklist rating scale (the SCL-90R, reference 44), one study compared psychiatric symptomatology in two groups of 32 subjects, one group taking efavirenz and the other taking protease inhibitors. In that study, all subjects were on their respective regimens for a minimum of four weeks for a mean of 45 weeks. The study found no significant differences in psychiatric symptomatology between the groups, although there were trends for increased scores on the anxiety $(\mathrm{P}=0.06)$ and hostility $(\mathrm{P}=0.09)$ scales in the efavirenz group using multivariate analyses (45).

In summary, the clinical trials and community evaluation studies suggest that neuropsychiatric side effects occur in $34 \%$ to $54 \%$ of subjects on efavirenz-containing regimens, with a discontinuation rate of $2.6 \%$ to $16 \%$ due to psychiatric side effects. The reported side effects differ across studies, with some reporting high rates of depression and others not. It appears that a lifetime history of mental health and substance-related disorders is not in and of itself a risk factor for the emergence of psychiatric side effects, particularly if the mental health disorder is being adequately treated. It also appears that emergent psychiatric symptomatology may be adequately managed with standard psychiatric interventions and/or discontinuation of efavirenz. Based on their review of data from controlled trials, the Therapeutics Products Program of Health Canada has required a warning notation on the Sustiva (efavirenz) product monograph (12), which states that patients with psychiatric histories appear to be at increased risk for serious psychiatric effects. It should be noted, however, that prior psychiatric history is not a contraindication to the use of efavirenz. Continued study of this issue is essential, and data including symptoms associated with longer term usage will continue to be evaluated. A large prospective study is currently underway which will more rig- orously ascertain the incidence rate, nature, time course and treatment of emergent neuropsychiatric side effects associated with antiretroviral therapies including efavirenz (personal communication, D Clifford, principal investigator, ACTG 5095 substudy).

\section{TREATMENT AND MANAGEMENT OF MAJOR DEPRESSION}

Once major depression is identified, it is important to develop a treatment plan. Mild to moderate depression may respond to psychotherapy alone, but a more severe symptom complex will require psychopharmacological intervention $(20,46,47)$. Antidepressant agents can be safely and effectively prescribed for patients with HIV/AIDS (27), and it is important not to undertreat with antidepressants on the basis of a concurrent medical disorder or the use of multiple medications when significant depressive symptoms are present. In patients taking multiple medications, including antiretroviral agents, some caution is needed in view of greater potential for drug interactions. In all treatments, the combination of medication and psychotherapy may prove most effective in reducing symptoms, limiting relapse and fostering psychological adaptation to illness. Endocrinological and metabolic disturbances may complicate the advanced stages of HIV disease and contribute to depressive symptomatology. As such, before antidepressant therapy is initiated, baseline blood tests should be performed, including complete blood count, electrolytes, fasting glucose, liver function tests, thyroid-stimulating hormone levels (48), vitamin $\mathrm{B}_{12}$ levels (49) and free testosterone levels (50), and an electrocardiogram, if tricyclic antidepressants (TCAs) are being considered.

The various classes of antidepressant medications exert different effects on the brain receptor sites for norepineprhine, serotonin and dopamine, which are all implicated in the pathophysiology of depression (51-54). Modulation of these neurotransmitter systems using selective serotonin reuptake inhibitors (SSRIs), serotoninnorepinephrine reuptake inhibitors, TCAs and dopamine reuptake inhibitors can improve depression and its related symptoms (53). Both TCAs and SSRIs have been evaluated in patients with HIV/AIDS and major depression. Data from randomized, double-blind, placebo controlled studies show similar response rates for the two classes of agents, ranging from $65 \%$ to $80 \%(47,55-58)$. While efficacy rates are comparable, the SSRIs are significantly better tolerated. In general, the increased propensity to treatment-emergent side effects with the HIV/AIDS population dictates that antidepressants should be initiated at low dose (generally half the recommended starting dose in the general population) and increased more slowly to ensure tolerability, but therapeutic treatment and maintenance doses are the same as in the general population $(18,54)$.

SSRIs: The SSRIs fluoxetine $(47,59,60)$, paroxetine $(55,61)$ and sertraline (57) are all effective for major depression and are well tolerated, even in patients with advanced HIV disease (2). In a double-blind, eight-week, placebo controlled 
trial, Rabkin et al (47) found a $57 \%$ response rate to fluoxetine in an intent-to-treat analysis and a $74 \%$ response rate among completers (versus placebo rates of $41 \%$ and $47 \%$, respectively). Elliot et al (62) reported superior efficacy with both paroxetine and imipramine compared with placebo in a randomized study; however, paroxetine appeared to be better tolerated. Halman et al (61) reported a complete response rate of $60 \%$ using an intent-to-treat analysis using paroxetine in patients with HIV/AIDS participating in a community effectiveness depression treatment trial.

Although potential drug interactions exist between SSRIs (particularly fluoxetine and nefazadone) and some antiretrovirals due to competition for P450 3A3/4 metabolism (63), many of these interactions appear to be clinically insignificant (64). The dosing principle of starting low applies with SSRIs. Paroxetine, fluoxetine or citalopram should be started at dosages of $10 \mathrm{mg}$ /day and increased to a standard dose of $20 \mathrm{mg}$ after seven to 10 days. (Sertraline may be initiated at 25 to $50 \mathrm{mg}$ and increased to 100 to $200 \mathrm{mg}$.) Common side effects include nausea and headache at the outset of treatment, which generally subside after the first two weeks of treatment. Other side effects may include sleep disruption and insomnia, fatigue, sweating, agitation, and dry mouth. Sexual dysfunction, including decreased libido, difficulty maintaining an erection and delayed ejaculation or anorgasmia, is a problematic side effect that is dose related and tends not to improve over time. For many patients, as their depression improves, antidepressant-associated sexual side effects become a barrier to continued treatment compliance. Overall, however, the SSRI agents are very effective and well tolerated, and have emerged as the first-line antidepressant treatment in depressed HIV-positive patients. All agents in this class are equally effective. Paroxetine appears to have the greatest anxiolytic effect but also has the most anticholinergic side effects. Fluoxetine is the most likely to cause agitation and has the longest half-life, which may pose problems in patients on multiple medications. Nefazadone, an SSRI with postsynaptic 5HT2 blockade, has been shown to be useful in moderately depressed patients with HIV (55), is sedating and is reported to cause sexual dysfunction less frequently than the traditional SSRI agents. However, in clinical practice, it has proved less useful in more severely depressed patients and, as a potent inhibitor of cytochrome $\mathrm{P} 450$ 3A3/4 isoenzyme, is one agent that frequently causes clinically significant drug interactions with protease inhibitors and non-nucleoside reverse transcriptase inhibitors (NNRTIS).

TCAs: TCAs have been found to be effective in patients with HIV infection. In a double-blind, placebo controlled trial, Rabkin et al (56) found a 74\% response rate among patients with HIV infection who received imipramine compared with a response rate of $26 \%$ among placebo-treated control subjects. TCAs may have an advantage over SSRIs in the most severe depressions; however, the use of TCAs is significantly limited by associated side effects including orthostatic hypotension, sedation and anticholinergic side effects, including confusion, constipation, blurred vision and urinary hesitancy impairment (18). TCAs are associated with more cardiac conduction abnormalities than SSRIs and have a high lethality in overdose (65). Treatment should be initiated with the lowest dose available and titrated upwards every two to three days as tolerated to normal therapeutic dosages. The antidepressant response course is similar to that seen with SSRIs. TCAs are metabolized primarily by the CYP450 2D6 system, and agents that inhibit CYP450 2D6 may increase TCA levels. Clinically significant interactions are most notable with ritonavir, which is a potent inhibitor of multiple CYP450 systems. Increased serum levels of desipramine have been reported when coadministered with ritonavir if ritonavir is being added to a stable regimen of desipramine (and theoretically ritonavir may increase the levels of other TCAs, including amitriptyline, clomipramine, doxepin, imipramine and nortriptyline). TCA dose reduction by one-third to one-half should be considered to avoid TCArelated toxicity. TCA serum levels can be accurately monitored, which is particularly helpful when patients do not have a predicted response, develop limiting side effects or are taking antiretroviral medications that may result in unusually high serum levels.

Other antidepressant agents: Although no published studies have evaluated newer antidepressants such as venlafaxine and bupropion, these agents are clinically useful, available in once daily, extended-release preparations and well tolerated in patients with HIV/AIDS. Venlafaxine is a dual serotonin and norepinephrine reuptake inhibitor (54). Side effects of venlafaxine are similar to those of SSRIs, and at higher doses, it may cause activating effects. Venlafaxine is often associated with nausea and gastrointestinal distress, and can cause a clinically significant rise in blood pressure, making it problematic in patients with hypertension $(18,54,66)$. Venlafaxine appears to have few clinically significant interactions with HIV medications, although levels may increase when used with ritonavir or decrease when used with nevirapine or efavirenz (63). Dosing with the sustained release formulation starts at $37.5 \mathrm{mg}$ daily and can be increased to a treatment dose of 75 to $225 \mathrm{mg}$ daily. It is important to remind patients not to break or crush extendedrelease preparations in order to maintain the integrity of appropriate drug release.

Bupropion is a dopamine reuptake inhibitor that may have specific benefits for patients with significant apathy and fatigue (67). It is reported to cause little sexual dysfunction and is, therefore, appealing to many patients. It is, however, a highly activating antidepressant in many patients, and can cause difficulties with anxiety, insomnia, tremor and agitation. Patients can often determine within a few days of starting the medication whether they will be able to tolerate it. Bupropion has a narrow window between therapeutic and toxic levels, so patients should be instructed clearly in the correct usage and dosing. Buproprion has been associated with seizures in patients at high risk for seizures, including those with a history of seizure disorder, eating disorders or brain injury, or on other medications that may lower the 
seizure threshold (18). There is no literature on patients with HIV/AIDS taking bupropion, but patients with advanced HIV disease may have many of the risk factors for lowered seizure threshold, necessitating caution when using this medication. Bupropion is metabolized by the cytochrome P450 2B6 system, and levels may be increased when used with ritonavir, although the clinical impact of this interaction is unclear. Buproprion is available in a sustained release formulation. Starting dose is $100 \mathrm{mg}$ daily and therapeutic dose is $150 \mathrm{mg}$ daily. To minimize risk of seizures, the daily dose should not exceed $300 \mathrm{mg}$, and any single dose should not exceed $150 \mathrm{mg}$. Patients should not take this drug if they are also taking Zyban (GlaxoSmithKline, Canada) for smoking cessation because it is the same active agent and will result in inadvertent overdose (68).

\section{ADMINISTRATION AND MONITORING OF ANTIDEPRESSANT THERAPY}

The time course for response is the same for all classes of antidepressants. In general, patients should experience a decrease in anxiety and depressive symptoms after being on an agent at a therapeutic dose for four to six weeks (46). Antidepressants are generally most effective for a circumscribed major depressive episode, yielding a remission rate of approximately $70 \%$. Complicating factors, including comorbid substance-related disorders, medical conditions, comorbid personality disorder, and chronicity and severity of the major depression, are associated with persistence of symptoms and reduced antidepressant effectiveness (69). Patients require considerable psychoeducation and support through the initial period of starting an antidepressant, because it is estimated that approximately $40 \%$ to $50 \%$ of patients will not take the medication for the minimum period required to detect any improvement (70). Patients should be monitored for emergent symptoms of antidepressant-induced mania that may develop in a small percentage of depressed patients, particularly those with a personal or family history of bipolar mood disorder or subsyndromal mood instability. Major depression is an important risk factor for suicide, and as such, monitoring of suicidal ideation, intent and plan, and ensuring patient safety are critical components of managing major depression. Risk factors for suicide, in addition to major depression, include social isolation, substance or alcohol-related disorders, personal and family history of suicide attempts, a perceived lack of social support, the experience of HIV-related social or occupational discrimination, recent diagnosis of HIV infection, or progression of symptomatic HIV/AIDS $(32,71)$. Patients with major depression need to be seen frequently at the outset of treatment for monitoring, support and reassurance. Prescriptions should be limited to small quantities to avoid lethal overdose in potentially suicidal patients.

Typically an antidepressant response should occur over the first four to six weeks, with a notable reduction in anxiety symptoms as early as the first week of treatment and improvement of mood and neurovegetative symptoms of depression thereafter (72). Because of efficacy, ease of administration and tolerability, the SSRIs have emerged as the antidepressants of first choice. Lack of response at week 6 should prompt a dosage increase if tolerated. Patients who have not responded or who have had intolerable side effects with one SSRI may have a better effect with a second SSRI. Failure with two SSRI medications should prompt a switch to a different class of antidepressant or employment of standard antidepressant augmentation strategies (73). In addition to standard augmentation strategies, depressed patients with later stage HIV/AIDS may benefit from adjuvant treatment with testosterone replacement $(74,75)$ and or stimulant (methylphenidate) augmentation (76). Many patients with major depression may be managed in primary care settings. Referral to a psychiatrist is advised in those patients who are unresponsive to trials of more than one or two medications, in those requiring augmentation or adjuvant strategies, in individuals with a history of mania or psychosis, or in patients with significant self-harm potential (20).

Once depression symptoms are relieved, antidepressant therapy should be continued for a minimum of nine to 12 months to avoid relapse and/or recurrence, or longer, up to an indefinite maintenance period, if the patient has had multiple prior depressive episodes (77). Psychotherapeutic approaches may be combined with antidepressant medications to most effectively reduce symptoms, reduce relapse, and facilitate healing, coping and adaptation.

\section{DRUG INTERACTIONS BETWEEN ANTIRETROVIRAL AGENTS AND PSYCHOTROPICS}

To assess potential for drug interactions, it is essential to know whether the agents are metabolized by the cytochrome P450 (CYP450) system and whether they induce or inhibit one or more of the isoenzyme metabolic systems. Most antidepressants, protease inhibitors and NNRTIs are metabolized by one or more of the CYP450 isoenzymes, whereas the nucleoside reverse transcriptase inhibitors are not (18). In general, ritonavir is the most potent inhibitor of multiple enzyme systems, the other protease inhibitors are less potent inhibitors, and the NNRTIs efavirenz and nevirapine are inducers under in vivo conditions. Although many theoretical drug interactions exist, the majority are not clinically problematic (64,72).

Clinically, an important interaction occurs when a psychotropic inducer is added to a stable antiretroviral regimen, resulting in lowered levels of the antiretroviral agent and loss of viral suppression. Agents that may cause this include the herbal remedy for depression, St John's Wort (78), phenytoin and carbamazepine. Psychotropic agents, which are potent inhibitors of CYP450 3A isoenzymes, eg, nefazadone or norfluoxetine (metabolite of fluoxetine), will result in increased levels of antiretroviral agents and may precipitate toxicity. Similarly, in patients on stable psychotropic regimens, the addition of HAART agents, which are potent inhibitors of these agents, will result in toxicity. The most notable clinically significant interaction is the addition of 


\section{TABLE 3}

Behavioural approaches to improving sleep hygiene

\section{Strategies}

Do:

- Maintain regular sleep/wake habits (ie, wake up at same time and go to bed at same time everyday).

- Exercise during the day.

- Sleep only enough to be refreshed.

- Maintain a cool, dark sleep area.

- Keep the bed for sleeping. If you cannot sleep after 20 mins, get out of the bed for a period of 10 or 15 mins rather than staying in bed tossing and turning.

- Relaxation exercises.

\section{Avoid:}

- Exercise in evenings.

- Going to bed with a full stomach.

- Caffeine, nicotine and alcohol in evenings.

- Noise and extremes of temperature in bedroom.

- Staying in bed for prolonged periods if you can't sleep.

- Letting the mind associate the bed with activities of wakefulness.

- Reading and watching television in bed.

Adapted from reference 84

ritonavir to TCAs or nefazadone. HAART agents that are potent inducers, including efavirenz and nevirapine, could result in subtherapeutic levels of psychotropics. Examples of clinically significant induction interactions include efavirenz or nevirapine added to methadone $(79,80)$.

\section{MANAGEMENT OF SLEEP COMPLAINTS}

Sleep complaints, insomnia and fatigue are common, and reported by as many as $70 \%$ to $80 \%$ of patients with HIV disease $(81,82)$. Frequently, physiological and psychological factors coexist and contribute to sleep difficulties. Most psychiatric disorders, including major depression, delirium, psychosis, substance-related disorders and pain disorder, can cause sleep complaints (81). Many of the medications used in patients with HIV disease can cause sleep disturbances, including cotrimoxazole, acyclovir, zidovuline, ddI, abacavir and efavirenz. With efavirenz, patients frequently complain of poor sleep quality and vivid dreams, and more rarely, frank insomnia.

Management of the condition comprises the treatment or correction of secondary causes to the extent possible, behavioural interventions and pharmacotherapy. Behavioural interventions (Table 3) include improving sleep hygiene, structuring sleep-wake cycles, relaxation techniques and the elimination of the use of psychoactive substances, including caffeine, nicotine, alcohol and other activating drugs (83-85). Sedative hypnotics, both benzodiazepine- and nonbenzodiazepine-based, can be useful for management of sleep disorders. While the goal is to use hypnotics for the short term only, for many patients, insomnia is a chronic problem and the physiological contributor cannot be corrected. In such cases, more chronic hypnotic use is often necessary, and a well discussed, judicious plan needs to be worked out to manage sleep without leading to the development of tolerance and dependence. Useful agents, particularly for initial insomnia, may include zopiclone $7.5 \mathrm{mg}$, clonazepam 0.5 to $1 \mathrm{mg}$, lorazepam 0.5 to $1 \mathrm{mg}$ or oxazepam 15 to $30 \mathrm{mg}$. Longacting benzodiazepines are associated with increased accu- mulation toxicities and drug interactions in patients with HIV/AIDS, and are better avoided (67). Low doses of the sedating antidepressant trazodone are also useful in treating patients with sleep disorders. Trazadone in doses starting at $25 \mathrm{mg}$ and up to $150 \mathrm{mg}$ at bedtime may be very helpful in overcoming middle insomnia, in which the patient is able to fall asleep but wakes after only a few hours of sleep. Trazodone is well tolerated in low doses, but patients should be advised of the risk of priapism and orthostatic hypotension (66). Sleep problems are frequently associated with major depression and terminal insomnia; early morning wakening is a classic sign of major depression. Management of sleep complaints should ensure that the presence of major depression is assessed and treated, if present. Antidepressant treatment, including activating antidepressants, is associated with a significant decrease in sleep complaints in most but not all depressed patients (85). Frequently, a combination of an antidepressant with either a benzodiazepine or trazodone is required to manage both sleep complaints and symptoms of major depression. Sleep complaints that do not respond to standard interventions may require input from a sleep specialist and polysomnographic evaluation to rule out primary sleep disorders.

\section{MANAGEMENT OF AGITATION}

Agitation in patients with HIV/AIDS may be due to many factors. Most commonly, agitation is due to anxiety or depression. Patients with substance-related disorders may present with agitation, particularly in states of intoxication or withdrawal. Agitation is a classic symptom in patients with schizophrenia, manic disorders and other psychotic disorders, and is a common symptom in patients with personality structures characterized by mood instability and impulsivity. Agitation may also be due to medical conditions, including pain and respiratory distress, and may be associated with medications including efavirenz.

Treatment is targeted towards the specific etiology. Often a supportive, empathic, structured environment can provide 
significant reassurance, allowing agitation to diminish. For an acute crisis period of circumscribed duration, anxiolytics are helpful in managing agitation. When agitation is related to depression, treatments for major depression are necessary. For patients with psychotic disorders, antipsychotics are the treatment of choice. Patients with HIV/AIDS have been shown to be highly sensitive to extrapyramidal side effects associated with typical antipsychotics such as haloperidol $(86,87)$. Novel antipsychotics, such as olanzapine, are clinically well tolerated but have not been systemically studied in patients with HIV/AIDS. In addition to their use in psychotic disorders, novel antipsychotics may have a role in managing agitation in patients who do not have psychotic disorders but who are prone to agitation, impulsivity and affective instability, although this is not yet a recognized treatment indication for this class of drugs (67). Because of the sensitivity to antipsychotics in patients with HIV/AIDS, starting doses should be low and increased slowly. Haloperidol may be started at doses of 0.5 to $1 \mathrm{mg}$, and olanzapine may be started at $2.5 \mathrm{mg}$. Side effects are common, and include extrapyramidal movement disorders, such as tardive dyskinesia with the typical antipsychotics, and significant weight gain with olanzapine. Patients with chronic psychotic disorders require long term maintenance antipsychotic use. In patients with nonpsychotic disorders, antipsychotic use should be limited in duration, being tapered quickly after resolution of the crisis period. If agitation is a result of a medication side effect and is not time limited, the medication should be discontinued rather than subjecting a patient to chronic antipsychotic use.

\section{CONCLUSIONS}

Neuropsychiatric symptoms, particularly depression, in patients with HIV/AIDS are common, and are frequently associated with multiple factors, including premorbid psychiatric history and diathesis, psychosocial factors, medical illness and medication side effects. With the evolving nature of HIV/AIDS into a chronic manageable illness, management of psychiatric symptoms has become an integral component of comprehensive HIV care. Successful treatment of major depression in patients with HIV/AIDS is well documented and can be safely instituted. More research is required in the optimum treatment of antiretroviral medication-related neuropsychiatric side effects, but growing clinical practice suggests that treatment-emergent side effects can be successfully managed using standard psychiatric interventions.

\section{REFERENCES}

1. Balderson K, Halman M, Jones K. Psychiatric aspects of HIV disease. Prim Care Psychiatry 2000;6:83-92.

2. Ferrando SJ, Goldman JD, Charness WE. Selective serotonin reuptake inhibitor treatment of depression in symptomatic HIV infection and AIDS. Improvements in affective and somatic symptoms. Gen Hosp Psychiatry 1997;19:89-97.

3. American Psychiatric Association. Diagnostic and Statistical Manual of Mental Disorders, Fourth edition, text revision. Washington, DC: American Psychiatric Association, 2000.
4. Worth JL, Halman MH. HIV disease/AIDS. In: Rundell JR, Wise MG, eds. American Psychiatric Press Textbook of Consultation-Liaison Psychiatry. Washington, DC: American Psychiatric Press, 1996:832-77.

5. Enzensberger $W$ for the German Neuro-AIDS study group (DNAA). Antiretroviral therapy (ART) from a neurological point of view. Eur J Med Res 1999;4:456-62.

6. 3TC Product Monograph. Mississauga: Glaxo Wellcome Inc, 1999.

7. Rachlis A, Fanning MM. Zidovudine toxicity. Clinical features and management. Drug Saf 1993;8:312-20.

8. Retrovir Product Monograph. Mississauga: Glaxo Wellcome Inc, 2000.

9. Valentine AD, Meyers CA, Kling MA, et al. Mood and cognitive side effects of interferon-alpha therapy. Semin Oncol 1998;25(Suppl 1):39-47.

10. Ruiz NM, Bessen LJ, Manion DJ, et al. Potential adverse experiences associated with efavirenz (EFV, Sustiva) in adults. Sixth Conference on Retroviruses and Opportunistic Infections. Chicago, January 31 to February 4, 1999. (Abst 655)

11. Staszewski S, Morales-Ramirez J, Tashima KT, et al. Efavirenz plus zidovudine and lamivudine, efavirenz plus indinavir, and indinavir plus zidovudine and lamivudine in the treatment of HIV-1 infection in adults. N Engl J Med 1999;341:1865-73.

12. Sustiva Product Monograph. Mississauga: DuPont Pharma Inc, 2001.

13. Atkinson H, Grant I, Kennedy CJ, et al. Prevalence of psychiatric disorders among men infected with human immunodeficiency virus. Arch Gen Psychiatry 1988;45:859-64.

14. Kelly B, Raphael B, Judd F, et al. Psychiatric disorder in HIV infection. Aust N Z J Psychiatry 1998;32:441-53.

15. Maj M, Janssen R, Starace F, et al. WHO neuropsychiatric AIDS study, cross sectional phase I. Study design and psychiatric findings. Arch Gen Psychiatry 1994;51:39-49.

16. McDaniel JS, Fowlie E, Summerville MB, et al. An assessment of rates of psychiatric morbidity and functioning in HIV disease. Gen Hosp Psychiatry 1995; 17:346-52.

17. Perkins DO, Stern RA, Golden RN, et al. Mood disorders in HIV infection: prevalence and risk factors in a nonepicenter of the AIDS epidemic. Am J Psychiatry 1994;151:233-6.

18. Penzak SR, Reddy YS, Grimsley SR. Depression in patients with HIV infection. Am J Health Syst Pharm 2000;57:376-86.

19. Kessler RC, McGonagle KA, Zhao S, et al. Lifetime and 12-month prevalence of DSM-III-R psychiatric disorders in the United States. Results from the National Comorbidity Survey. Arch Gen Psychiatry 1994;51:8-19.

20. Whooley MA, Simon GE. Managing depression in medical outpatients. N Engl J Med 2000;324:1942-9.

21. Hoover DR, Saah A, Bacellar H. The progression of untreated HIV-1 infection prior to AIDS. Am J Public Health 1992;82:1538-41.

22. Rabkin JG, Ferrando SJ, Lin SH, Sewell M, McElhiney M. Psychological effects of HAART: a 2-year study. Psychosom Med 2000;62:413-22.

23. Evans DL, Staab J, Ward H, et al. Depression in the medically ill: management considerations. Depress Anxiety 1996-97;4:199-208.

24. Weiner J. Is depression inevitable in the face of AIDS? AIDS Read 1996;6:66-72.

25. Hays RB, Turner H, Coates TJ. Social support, AIDS- 
related symptoms, and depression among gay men. J Consult Clin Psychol 1992;60:463-9.

26. Namir S, Wolcott D, Fawzy FI, et al. Coping with AIDS: psychological and health implications. J Appl Soc Psychol 1987;17:309-28.

27. Perry SW III. HIV-related depression. In: Price RW, Perry SW, eds. HIV, ADIS and the Brain. New York: Raven Press Ltd, 1994:223-38.

28. Rabkin J, Ferrando S. A 'second life' agenda: psychiatric research issues raised by protease inhibitor treatments for people with human immunodeficiency virus or the acquired immunodeficiency syndrome. Arch Gen Psychiatry 1997;54:1049-53.

29. Lesserman J, Jackson ED, Petitto JM, et al. Progression to AIDS: the effects of stress, depressive symptoms, and social support. Psychosom Med 1999;61:397-406.

30. Simon GE, Katon W, Rutter C, et al. Impact of improved depression treatment in primary care on daily functioning and disability. Psychol Med 1998;28:693-701.

31. Fawcett J, Scheftner WA, Fogg L, et al. Time-related predictors of suicide in major affective disorder. Am J Psychiatry 1990;147:1189-94.

32. Rundell JR, Kyle KM, Brown GR, Thomason JL. Risk factors for suicide attempts in a human immunodeficiency virus screening program. Psychosomatics 1992;33:24-27.

33. Mayne TJ, Vittinghoff E, Chesney MA, Barrett DC, Coates TJ. Depressive affect and survival among gay and bisexual men with HIV. Arch Intern Med 1996;156:2233-8.

34. Evans DL, Lesserman J, Perkins DO, et al. Severe life stress as a predictor of depression in HIV infection. Am J Psychiatry 1997;154:630-4.

35. Chesney MA. Factors affecting adherence to antiretroviral therapy. Clin Infect Dis 2000;30(Suppl 2):S171-6.

36. Paterson DL, Swindells S, Mohr J, et al. Adherence to protease inhibitor therapy and outcomes in patients with HIV infection. Ann Intern Med 2000;133:21-30.

37. Gordillo V, del Amo J, Soriano V, Gonzalez-Lahoz J. Sociodemographic and psychological variables influencing adherence to antiretroviral therapy. AIDS 1999;13:1763-9.

38. Catz SL, Kelly JA, Bogart LM, Benotsch EG, McAuliffe TL. Patterns, correlates, and barriers to medication adherence in persons prescribed new treatments for HIV disease. Health Psychol 2000;19:124-33.

39. Carr A, Cooper DA. Adverse effects of antiretroviral therapy. Lancet 2000;356:1423-30.

40. Haas DW, Fessel WJ, Delapenha RA, et al. Therapy with efaverenz plus indinavir in patients with extensive prior nucleoside reverse-transcriptase inhibitor experience: A randomized, double-blind, placebo-controlled trial. J Infect Dis 2001;183:392-400.

41. Parrish D, Godbey J. Use of efavirenz in a low income population. XIII International AIDS Conference. Durban, July 9-14, 2000. (Abst WePeB4138)

42. Max B, Garey K, Schwartz D, et al. Efavirenz (EFV) tolerability in the real world: relation to mental illness, alcohol, and illicit drug use in a large, urban HIV clinic. XIII International AIDS Conference. Durban, July 9-14, 2000. (Abst WePeB4288)

43. Goldenberg D, Boyle B. Psychiatric safety of efavirenz. XIII International AIDS Conference. Durban, July 9-14, 2000. (Abst WePeB4238)

44. Derogatis LR, Rickels K, Rock AF. The SCL-90 and MMPI: a step on the validation of a new self-report scale. Br J Psychiatry 1976;128:280-9.
45. Hawkins T, Grossman D, Haubrich R. CNS side effects of EFV may persist in patients thought to tolerate the drug. XIII International AIDS Conference. Durban, July 9-14, 2000. (Abst WePpB1377)

46. Depression Guideline Panel. Depression in Primary Care: Vol 2. Treatment of Major Depression. Clinical Practice Guideline, Number 5. AHCPR Publication No 93-0551. Rockville: US Department of Health and Human Services, Public Health Service, Agency for Health Care Policy and Research, 1993.

47. Rabkin JG, Wagner GJ, Rabkin R. Fluoxetine treatment for depression in patients with HIV and AIDS: a randomized, placebo-controlled trial. Am J Psychiatry 1999;156:101-7.

48. Grunfeld C, Pang M, Doerrler W, et al. Indices of thyroid function and weight loss in HIV infection and AIDS. Metabolism 1993;42:1270-6.

49. Beach RS, Mantero-Atienza E, Shor-Posner G, et al. Specific nutrient abnormalities in asymptomatic HIV-1 infection. AIDS 1992;6:701-8.

50. Grinspoon SK, Bilezikian JP. HIV disease and the endocrine system. N Engl J Med 1992;327:1360-5.

51. Richelson E. Basic neuropharmacology of antidepressants relevant to the pharmacotherapy of depression. Clin Cornerstone 1999;1:17-30.

52. Richelson E. Pharmacology of antidepressants characteristics of the ideal drug. Mayo Clin Proc 1994;69:1069-81.

53. Stahl SM. Basic psychopharmacology of antidepressants, part 1: Antidepressants have seven distinct mechanisms of action. J Clin Psychiatry 1998;59(Suppl 4):5-14.

54. Stahl SM. Selecting an antidepressant by using mechanism of action to enhance efficacy and avoid side effects. J Clin Psychiatry 1998;59(Suppl 18):23-9.

55. Elliot AJ, Uldall KK, Bergam K, et al. Randomized, placebo-controlled trial of paroxetine versus imipramine in depressed HIV positive outpatients. Am J Psychiatry 1998; 155:367-72.

56. Rabkin JG, Rabkin R, Harrison W, et al. Effect of imipramine on mood and enumerative measures of immune status in depressed patients with HIV illness. Am J Psychiatry 1994;151:516-23.

57. Rabkin JG, Wagner G, Rabkin R. Effects of sertraline on mood and immune status in patients with major depression and HIV illness: an open trial. J Clin Psychiatry 1994;55:433-9.

58. Zisook S, Peterkin J, Goggin KJ, et al. Treatment of major depression in HIV-seropositive men. J Clin Psychiatry 1998;59:217-24.

59. Hintz S, Kuck J, Peterkin JJ, et al. Depression in the context of human immunodeficiency virus infection: implications for treatment. J Clin Psychiatry 1990;51:497-501.

60. Levine S, Anderson D, Bystritsky A, et al. A report of eight HIV-seropositive patients with major depression responding to fluoxetine. J Acquir Immune Defic Syndr 1990;3:1074-7.

61. Halman MH, Sota T, Rourke SB. Paroxetine for HIVrelated depression: impact on mood, quality of life and cognition. 10th Annual Conference of the Canadian Association of HIV/AIDS Research. Toronto, May 31 to June 3, 2001. (Abst 295P)

62. Elliot AJ, Uldall KK, Bergam K, et al. Randomized, placebo-controlled trial of paroxetine versus imipramine in depressed HIV positive outpatients. Am J Psychiatry 1998; 155:367-72.

63. Ereshefsky L, Riesenman C, Lam YW. Serotonin selective reuptake inhibitor drug interactions and the cytochrome P450 system. J Clin Psychiatry 1996;57(Suppl 8):17-24. 
64. Bialer PA, Bluestine SL, Termine AW, et al. Psychiatric implications for AIDS patients taking protease inhibitors. Psychosomatics 1998;39:183-4.

65. Cole JO, Bodkin JA. Antidepressant side effects. J Clin Psychiatry 1990;51(Suppl):21-6.

66. Andrews JM, Nemeroff CB. Contemporary management of depression. Am J Med 1994;97(Suppl 6S):6S-24S.

67. Fernandez F, Levy JK. Psychopharmacology in HIV spectrum disorders. Psychiatr Clin North Am 1994;17:135-48.

68. Wellbutrin Product Monograph. Mississauga: Glaxo Wellcome Inc, 1999.

69. Sargeant JK, Bruce ML, Florio L, Weissman MM. Factors associated with 1-year outcome of major depression in the community. Arch Gen Psychiatry 1990;47:519-26.

70. Schulberg HC, Katon WJ, Simon GE, Rush AJ. Best clinical practice: guidelines for managing major depression in primary medical care. J Clin Psychiatry 1999;60(Suppl 7):19-26.

71. Kelly B, Raphael B, Judd F, et al. Suicidal ideation, suicide attempts, and HIV infection. Psychosomatics 1998;39:405-15.

72. Halman MH, Bialer P, Worth JL, et al. HIV Disease/AIDS. In: Rundell JR, Wise MG, eds. American Psychiatric Press Textbook of Consultation - Liaison Psychiatry, 2nd edn. Washington, DC: American Psychiatric Press. (In press)

73. Joffe RT, Singer W, Levitt AJ, et al. A placebo-controlled comparison of lithium and triiodothyronine augmentation of tricyclic antidepressants in unipolar refractory depression. Arch Gen Psychiatry 1993;50:387-93.

74. Rabkin JG, Rabkin R, Wagner G. Testosterone replacement therapy in HIV illness. Gen Hosp Psychiatry 1995; 17:37-42.

75. Wagner GJ, Rabkin JG, Rabkin R. A comparative analysis of standard and alternative antidepressants in the treatment of human immunodeficiency virus patients. Compr Psychiatry 1996;37:402-8.

76. Rabkin JG. Psychostimulant medication for depression and lethargy in HIV illness: a pilot study. Progress Notes 1993;4:1-4.
77. Thase ME. Relapse and recurrence in unipolar major depression: short-term and long-term approaches. J Clin Psychiatry 1990;51(Suppl 6):51-7.

78. Piscitelli SC, Burstein AH, Chaitt D, et al. Indinavir concentrations and St. John's wort. Lancet 2000;355:547-8. (Lett)

79. Tseng AL, Foisy MM. Significant interactions with new antiretrovirals and psychotropic drugs. Ann Pharmacother 1999;33:461-73.

80. Panel on Clinical Practices for the Treatment of HIV Infection. Guidelines for the use of antiretroviral agents in HIV-infected adults and adolescents. Washington, DC: US Department of Health and Human Services and the Henry J Kaiser Family Foundation. $<$ http://www.hivatis.org > (Version current at February 5, 2001)

81. Prenzlauer SL, Bogdonoff L, Tiamson MLA, et al. Sleep and HIV illness. IXth International Conference on AIDS. Berlin, June 6-11,1993. (Abst PO-B16-1752)

82. Rubinstein ML, Selwyn PA. High prevalence of insomnia in an outpatient population with HIV infection. J Acquir Immune Defic Syndr Hum Retrovirol 1998;19:260-5.

83. Thase ME. Treatment issues related to sleep and depression. J Clin Psychiatry. 2000;61(Suppl 11):46-50.

83. Holbrook AM, Corwther R, Lotter A, et al. The Diagnosis and management of insomnia in clinical practice: a practical evidence-based approach. CMAJ 2000;162:216-20.

84. Sammiudin Z. Insomnia in HIV and its management: one clinician's perspective. Res Initiative Treatment Action 2000;6:5-9.

85. Armitage R. The effects of antidepressants on sleep in patients with depression. Can J Psychiatry 2000;45:803-9.

86. Hriso E, Kuhn T, Masdeu JC, Grundman M. Extrapyramidal symptoms due to dopamine-blocking agents in patients with AIDS encephalopathy. Am J Psychiatry 1991;148:1558-61.

87. Sewell DD, Jeste DV, McAdams LA, et al. Neuroleptic treatment of HIV-associated psychois. HNRC group. Neuropsychopharmacology 1994;10:233-9. 


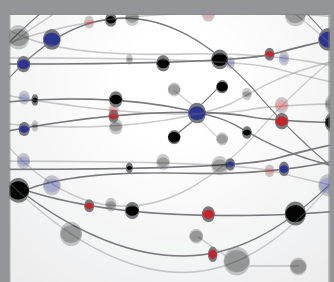

The Scientific World Journal
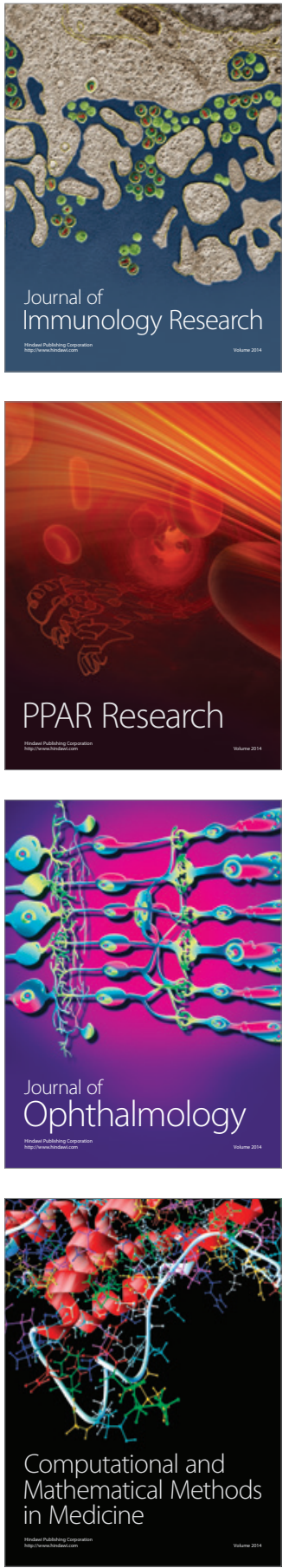

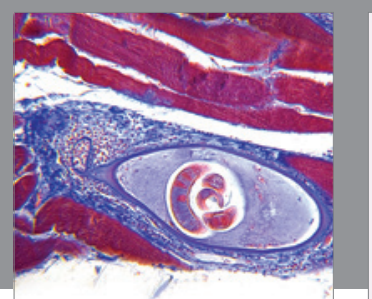

Gastroenterology Research and Practice

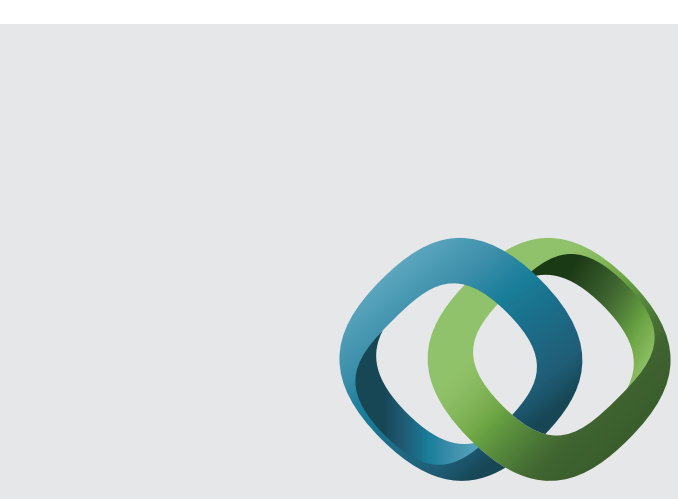

\section{Hindawi}

Submit your manuscripts at

http://www.hindawi.com
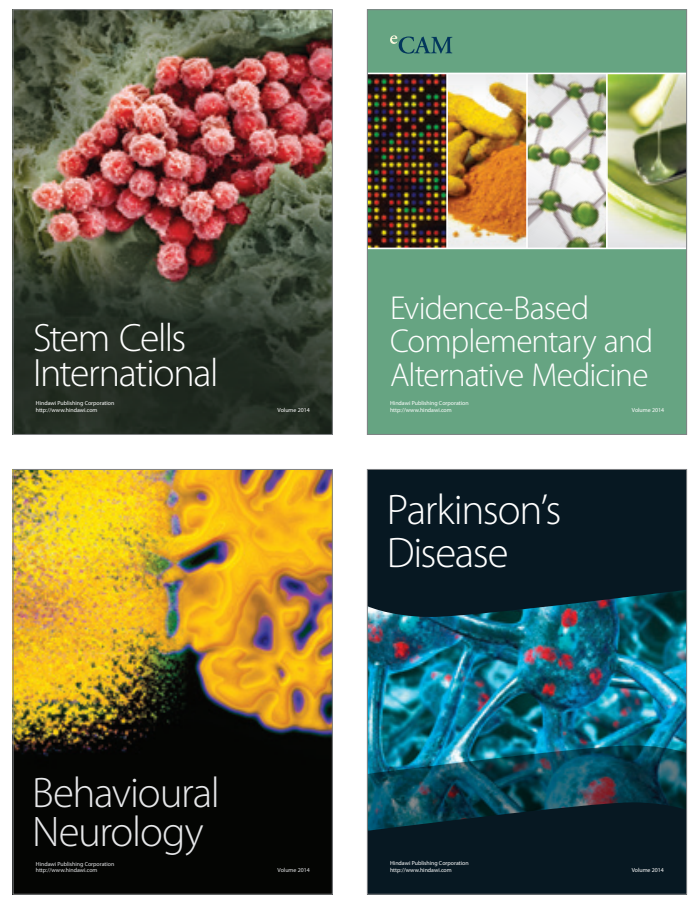
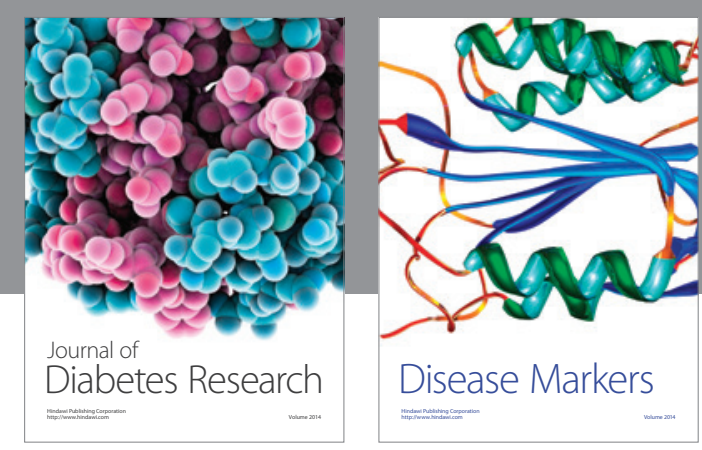

Disease Markers
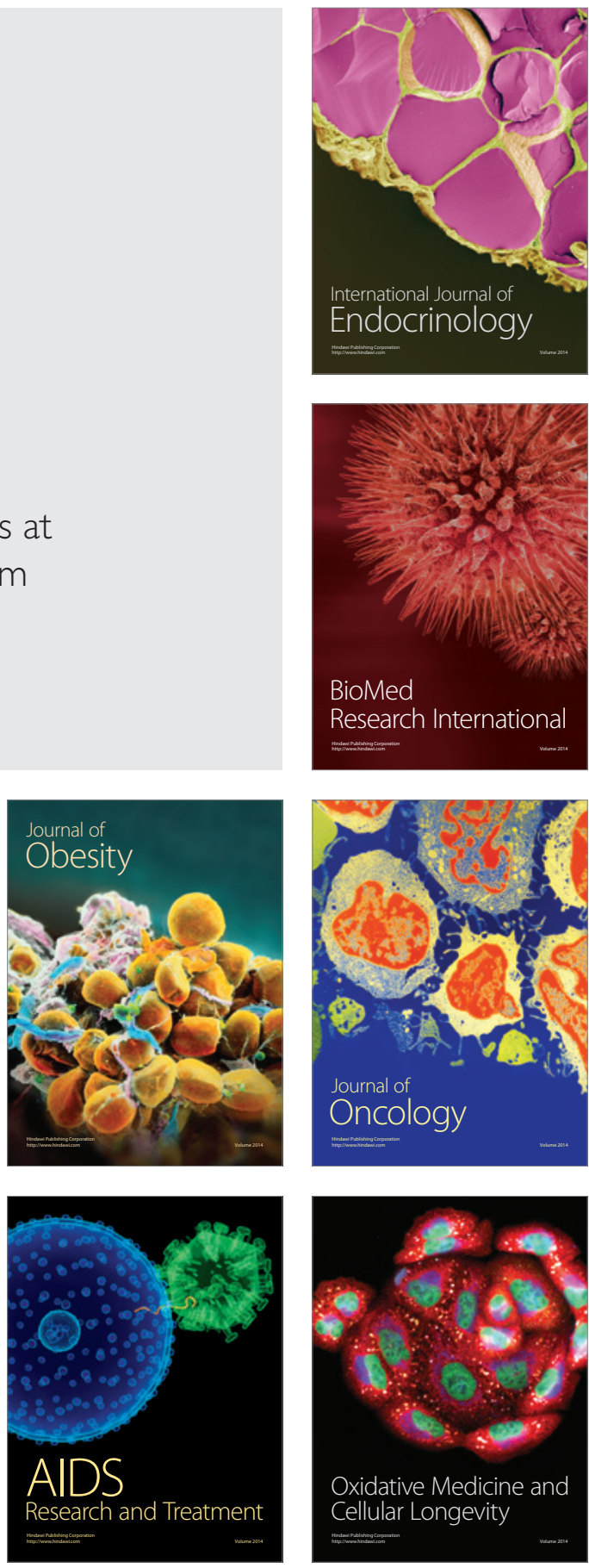